\title{
Understanding the factors that influence patient satisfaction with Emergency department in Moroccan hospital.
}

\author{
E. Bouaiti ${ }^{12}$, S. Zidouh ${ }^{3}$, A. Boufaress ${ }^{12}$, J. Kessouati $^{2}$, S. Elkafssaoui ${ }^{2}$, \\ M.Mrabet ${ }^{12}$, L. Belyamani ${ }^{3}$ \\ 1. Department of Public Health, Faculty of Medicine and Pharmacy of Rabat, Morocco. \\ 2. Department of hygiene and public health, Military Hospital Mohammed V, Rabat, Morocco \\ 3. Emergency Departement, Military Hospital Mohammed V, Rabat, Morocco
}

\begin{abstract}
Background:-Patient satisfaction with emergency department care is the most important predictor of overall satisfaction with their hospital care. The aim of the present study was to investigate the effective factors in Patients' satisfaction with the emergency department.

Methods:-A cross-sectional survey was carried out from April 2014 to July 2014. The study sample consisted of 330 patients visiting the emergency department of an urban tertiary level teaching hospital in Rabat, Morocco. Subjects were selected through simple random sampling method. Data was collected using a questionaire. whose validity was determined using the content validity. Reliability of the questionnaire was checked using Cronbach $\alpha$ coefficient. To identify the most important factors affecting patient satisfaction, factorial analysis technique was used.

Results:-More than $80 \%$ of patients expressed their positive overall satisfaction with the facility. The principal component analysis yielded 5 principal components with $82.6 \%$ of cumulative variance of patient satisfaction: (1) "pain management"; (2) "staffresponsiveness", (3) "Reception", (4) "waiting time", and (5) "administrative skills".

Conclusion:-Pain management and staff-responsiveness were the major factors affecting satisfaction in emergency patients. Thus improving the quality of these factors will improve the quality of emergency services for patients.
\end{abstract}

Keywords:-Emergency department, patient satisfaction, Morocco, principal component analysis.

\section{INTRODUCTION}

Patient satisfaction with Emergency department (ED) care is the most important predictor of overall satisfaction with their hospital care [1]. Highly satisfied patients are essential to the sustainability of any health care organization and dissatisfied clients are unlikely to recommend the facility to their network of family, friends and associates [2].In health care, patient satisfaction also impacts other key areas such as patient compliance and medico-legal risk [3,4]. Patient satisfaction is a summation of all the patient's experiences in the hospital. It derives from the patient's evaluation of how well the provider meets his or her personal and emotional as well as physical needs.

Patient satisfaction with their ED experience has been associated with a number of different predictor variables related to patient demographics and visit characteristics. However, certain aspects of care such as amenities, accessibility and the quality of interpersonal relationship between patients and caregivers can only be reliably assessed by measuring patient's satisfaction [5]. Interest in such measurements has grown recently because patient satisfaction has important implications for the financial status of the hospital, and for its professional reputation in the community [6]. Previous studies have suggested that patients' satisfaction is a major determinant of whether patients will patronize the health facility again [7].

Because it is such a complex topic, one of the most accepted ways of studying satisfaction is by using questionnaires in which the questions are organized into different dimensions or domains [8]. The relative importance of each index can be derived by assigning weights to the scores on the different dimensions.

Patient satisfaction among ED patients can be challenging to measure reliably. A recent literature review of patient satisfaction investigations in the ED found large variations in satisfaction measures [9]. The authors found that due to subjectivity of definitions, clinicians and investigators should standardize future investigations by using a common definition for the state of overall patient satisfaction (such as, "when the patient's own expectations for treatment and care are met or exceeded"). As of yet, there is no universally accepted definition of patient satisfaction. 
Only a few questionnaires have been developed to effectively measure patient satisfaction in developing countries. In addition, the measurement of patient satisfaction is affected by many variables and can be complex [10]. Cultural norms can be a big obstacle to patients' satisfaction as well as acceptance. Thus, contrary to typical Caucasian North American patients, female Hispanic patients in the USA were more satisfied with their treatment when family members were involved in the decision making. Studies have also shown that in multiracial environments, languages play a vital role in physician-patient interactions, and sometimes, physicians also compound the problem by overestimating the patients' abilities to comprehend instructions [11]. Patient satisfaction may not only be culturally dependent [12], but may also be impacted by many factors such as laws, regulations and healthcare systems, in which there are differences between Morocco and other countries. It has been measured in the literature by a variety of methods. Examples include: a global measure of satisfaction using a visual analogue scale (VAS); a multidimensional measure of satisfaction based on the Patient Satisfaction Questionnaire using an evaluation response format (poor, fair, good, very good, excellent); and a six-item attitude measure of general satisfaction using a Likert agree-disagree response format [13].

For these reasons, we needed to develop a common assessment tool that can be used to measure patients' satisfaction in many emergency departments in Moroccan hospitals. In the present study, we utilized a questionnaire in the Emergency department of a teaching hospital in Rabat, Morocco to determine the relative importance of different item to the overall satisfaction of the patient.

The aim of the present study was to determine the effective factors in patients' satisfaction with the emergency department in Moroccan hospital.

\section{2. METHODS}

\section{Design and study area}

This research was a cross-sectional study undertaken in the emergency department of the Moroccan military hospital (teaching hospital) in Rabat, from April to July 2014. Study participants who were over 18 years, who received emergency care and who agreed to participate in the study were included in the sampling pool. Critically ill patients and children were excluded from the study.

The patients were selected by the simple random sampling method. Sample size was determined by $\mathrm{p}=0.8$, $\mathrm{d}=0.05$ and confidence interval $95 \%$.

\section{Questionnaire}

Data was collected using a questionnaire whose validity was obtained using the content validity. The questionnaire included items on various aspects of inpatient care that play an important role in Patients' satisfaction as follows:

1) Socio- demographic component: age, gender, marital status and education.

2) Admission information: Reception and Waiting time items.

3) The relationship between patient and treatment providers: Pain management and Staff responsiveness items.

4) Accessibility and availability of administrative staff: Administrative skills items.

For each satisfaction item, the respondent was asked to rate his/her satisfaction level (I am satisfied with...) on a 4-point Likert-type scale from 1 (disagree strongly) to 4 (agree strongly). If he/she had no idea of a particular item, he or she selected the "not relevant/do not know" response option.

\section{Data collection}

Data was collected by a trained research doctor. Patients were approached in person and provided with the objectives and a brief description of the study. Informed consent was obtained before they were asked to answer the questionnaire.

The interviews were conducted after the patients had been treated by the doctor and cared for by the nursing staff. These and other measures were taken to ensure high ethical standards in the conduct of the study and reduce the possibility of bias.

\section{Data analysis}

Data were analyzed using IBM SPSS 19.0 for Windows (Chicago, Illinois). Descriptive as well as analytical analyses were employed to determine patients' level of satisfaction. Differences between categorical groups were determined using $\chi 2$ test and Mann-Whitney test was applied to continuous data as appropriate. Pvalues $<0.05$ were considered to be statistically significant in all analyses.

To find the most important dimensions of patient satisfaction, exploratory factor analysis was used. Extraction method in factor analysis was principal component analysis (PCA) with orthogonal Varimax rotation.

The significance of PCA loadings was determined according to the broken-stick criterion, which is described in detail by Peres-Neto et al. [14]. Reliability of the principal components produced was evaluated on the basis of 
their Cronbach's alpha values. Spearman and Pearson correlation coefficient was used to estimate the association between factor components and continuous variables.

\section{3. RESULTS}

\section{Description of socio demographic variables}

Between Apriland July 2014, we administered questionnaires to 330 patients made up of $68.2 \%$ $(n=225)$ males and 31.8\% $(n=105)$ females. Mean age of participants was $45.8 \pm 20.3$ (median = 40.4, IQ: 24.4 - 67.8 years), and the median duration of stay in Emergency department was 12.5 minutes ranging from 1 minute to 180 minutes (IQ=5 - 20 minutes).

Participants were mainly educated at the secondary $(31.8 \%, \mathrm{n}=105)$ and tertiary levels $(22.7 \%, \mathrm{n}=75)$. Table 1 summarizes socio-demographic characteristics of all study participants.

There was a significant association between patient satisfaction and gender, age, length of waiting time and education level $(\mathrm{p}<0.05)$.

\section{Patient satisfaction factors}

Six of the 17 patient satisfaction items were rated satisfied to very satisfied by more than $90 \%$ of respondents as illustrated in Table 2. The top three patient dissatisfied items were "Information given about health" (70.0\%), "Documents provided in emergency department" (70.0\%) and the "Ease of obtaining information in waiting area" $(61.5 \%)$. The Cronbach's $\alpha$ reliability estimate for the questionnaire used in this study was 0.864 , indicating that the reliability of the questionnaire was high. Quality of the data was assured by pretesting of the instrument, training of data collectors, coding and cleaning of data.

The principal component analysis with the Varimax rotation was applied to the responses to the items in the first Section. The Kaiser-Meyer-Olkin measure of sampling adequacy was 0.664, and Bartlett's test of sphericity was significant at $\mathrm{p}<0.001$, indicating that the data was appropriate for factor analysis.

The analysis yielded 5 principal components with $82.6 \%$ of cumulative variance in the patient satisfaction. The analysis result is summarized in Table 3 in terms of factor label, component items, their factor loadings, and Cronbach's alpha for each principal component. Internal reliability, as assessed by Cronbach's alpha, was sufficiently high for all the factors, i.e. > 0.70, which is a regular limit of acceptance level (Nunnaly, 1978).

As for the first principal component, items highly loaded were related to treatment received for pain, staff response to pain, and staff assessment of pain. Accordingly, we labeled this factor satisfaction with "pain management". In this way, we interpreted all 5 factors by highly loaded items as follows: (1) "pain management"; (2) "staff - responsiveness", (3) "Reception", (4) "waiting time", and (5) "administrative skills". For details, please refer to Table 3.

\section{Overall trend of emergency patients' satisfaction}

A mean score for each satisfaction factor was calculated over all component items for each respondent. The percentage of positive responses for a specific satisfaction factor is defined as a proportion of respondents having its mean score of 3.00 or greater.

The positive percentages of the satisfaction factors (Table 4), showed that more than $70 \%$ of patients provided positive ratings for most (4 out of 5) items, with the exception of "Reception" $(61.5 \%)$.

More than $80 \%$ of patients expressed their positive overall satisfaction with the facility, and $75 \%$ expressed a willingness to return to the current facilities. In addition, $70 \%$ were willing to recommend the facility to their family or friends who suffer from the same disease.

There is a significant relationship between the "Reception" dimension and the willingness to return to the facilities $\left(r=0.82, p<10^{-4}\right)$ and the willing to recommend the facility to others $\left(r=0.69, p<10^{-4}\right)$. The associations between factors of satisfaction using the Pearson correlation coefficient are presented in Table 4.

\section{DISCUSSION}

Our findings indicate that patients were content with the health care delivered in the emergency department, as a total of $80 \%$ of study participants reported that they were very satisfied or satisfied with the health care received. In comparison, $52 \%$ of patients were satisfied with nursing care in an Emergency Medicine Outpatient department of a tertiary care hospital in India [15]. Similarly, in Ghana, only 33\% of in-patients were fully satisfied with nursing care at a university hospital [16]. The demographic characteristics of participants in India differ from those in this study as the majority of those respondents had higher levels of education and were mostly males from rural areas. The socio-demographic characteristics of participants in Ghana were not described.Satisfaction factors of Emergency department patients elicited from our survey are partly composed of common factors present in other studies, e.g., interpersonal issues including interpersonal relations and communication between staff and patients to provide information and explanation; staff skills and expertise as technical concerns; administrative aspects such as staff responsiveness and reception [17]. One of the factors 
elicited, quality of document provided in emergency department, is unique for the Moroccan survey as they regard it as a source of their administrative problems.

Demographics, such gender, age and education level, play a role in patient satisfaction. A 2010 qualitative review of patient satisfaction studies suggests that older patients are more likely to express satisfaction than those who are younger [18]. This review also found that young age and African-American patients are even less satisfied with care. Thestudy indicated that the top three satisfaction items which patients were very satisfied concern patient - health worker relations: courtesy and how quickly staff responded to patients' requests. This is in congruence with other studies which found that caring, skills and competence and information given by nurses are important indicators of nursing care [19]. Conversely, the items that patients were reportedly least satisfied with in the emergency department were Information and document provided during the emergency care.

Low levels of satisfaction with information and instructions given by health workers have been reported in other settings. Lower levels of patient satisfaction often result from the use of technical medical language that is not understood by patients. Even ED nurses and physicians ranked "information, respect, and empathy" as most important areas to improve upon in a study in 2011 [20]. Another study found that successful communication between doctors and patients regarding the reasons for admission and test results can also be an important predictor of patient satisfaction [21].

The observed low satisfaction due to providers' lack of patient's information underlines the importance for hospital management to strengthen adherence skills among ED staff on communication and patients' interactions. Trout et al. [22] and Boudreaux [23], in separate review articles, concluded that important underlying determinants of emergency department patient satisfaction include information provision, interpersonal interactions, and perceived waiting time. Each of these factors is, in turn, related to staff-patient communication. Indeed, this is supported by numerous reports that have concluded that complaints related to communication comprise considerable proportions of all complaints received in both general hospital [24] and emergency department settings [25].

In this research, five factors explain $82.6 \%$ of the variation of Patients' satisfaction including satisfaction with pain management, staff responsiveness reception, waiting time and administrative skills. A study reported Patients' satisfaction as consisting of five factors, including: (i) doctor competency; (ii) provision of information; (iii) quality of care; (iv) waiting time; and (v) hospital [26]. Another study showed the significant relationships between interpersonal skills, technical quality of medical staff, especially nurses and physicians and general patient satisfaction [27]. A Japanese study found that the interpersonal skills and technical quality of health care providers are two unique dimensions involved in patient assessment [28].

Based on our results, satisfaction of pain management, staff responsiveness and reception were the most important aspect of satisfaction and explained $36.6 \%, 16.8 \%$ and $12.9 \%$ of overall satisfaction.

Aragon and Gesell's [29] examination of the Primary Provider Theory of Patient Satisfaction in the emergency department found that physician service, waiting time, and nursing satisfaction explained $48 \%, 41 \%$, and $11 \%$ of overall satisfaction.

Pain management dimension, which was used to assess the staff assessment of pain, staff response to pain, and treatment received in the Emergency Department for pain, was ranked first by respondents. These findings are consistent with aspects of certain previously published studies. It has been demonstrated that satisfaction is associated with the response of the ED staff to the patient's report of pain and the type of treatment received [30]. Thus, pain relief is related to patient satisfaction.Because treatment for pain and related conditions has been identified as the most common reason for ED visits, health care providers must practice effective pain assessment, treatment, and management strategies [31].

Pain assessment is an integral step of pain management; poor assessment often leads to poor treatment of pain. In some cases, physicians do not provide adequate analgesia to their patients, do not meet patients' expectations in treating their pain, and struggle to change their practice regarding analgesia [32].

The level of satisfaction with staff-patient relationship in the emergency department was a strong predictor of perception of overall satisfaction of patients in the emergency department. More than $84 \%$ of respondents reported that they were satisfied to very satisfied with Staff responsiveness dimensions of emergency care (courtesy, reactivity and technical skills) underscoring the importance of the patient - health worker relationship. Patients visiting the emergency department expect that they will meet helpful staff, that their needs will be considered and that they will be cared for quickly. These are areas which must be further explored in order to improve the quality of care in the emergency department.

Waiting time dimension, which was used to assess the perception of wait times, privacy and comfort of waiting area, was ranked second by respondents. Wait time is a key component of patient satisfaction, and significant efforts have been made to reduce ED wait times and increase overall ED efficiency [33]. During the wait period, early interactions with staff disproportionately affect the perception of the wait time. Negative interactions early in the wait period increase the perception of the overall wait time, whereas positive 
interactions have the opposite effect. Studies looking at repeat service interactions have shown that earlier interactions weigh more heavily on cumulative satisfaction with the service provider [34]. In the ED, registration staff, triage nurses, and greeters are important contacts early in a patient's service interaction. Customer service training to improve these early patient interactions may decrease the perception of wait time. Patient satisfaction is affected by patient non-clinical perceptions of their care environment and dependent upon staff effectively managing patient expectations. Design of the service environment (waiting area and cleanliness in the emergency department) is a key concept that can be leveraged to reduce patients' perception of wait times. Features of the service environment such as temperature, lighting, and noise level have all been individually shown to affect the wait experience [35]. Deviation of any of these factors from a level of comfort prolongs the perception of wait time and leads to patient unsatisfaction . Using photographs of 28 different waiting rooms, Arneill and Devlin [36] asked participants to rate how they perceived the quality of care to be delivered in those healthcare settings. Results showed that perceived quality of care was greater for waiting rooms that were nicely furnished, well-lighted, contained art-work, and were warm in appearance, versus waiting rooms that had outdated furnishings, were dark, contained no art-work or poor quality reproductions, and were cold in appearance.

Of all five factors used to assess patient's level of satisfaction, respondents were least satisfied with the Reception. Reception items which explained most of the dissatisfaction with quality of care were lack of availability of personnel in waiting area and ease of obtaining information in waiting area. The staff of emergency department, and registered nurses in particular, are primarily responsible for the patients' impression of the facility because they work in an area where patients have their first contact with the healthcare facility and which acts as the portal to the rest of the hospital.

The factors of global satisfaction were also analyzed to determine their association with participants' intention to recommend the emergency department to family and friends. The waiting time and reception dimensions were found to be strongly associated with participants' intention to recommend the department to others. Similar data have have been reported in previous studies [37].

\section{LIMITATIONS}

The present study used a convenience sample to examine patient satisfaction levels with care provided in a single emergency department in Morocco, and therefore is limited in its ability to predict patient satisfaction in other emergency departments in the country.

Bias could have been introduced because the questionnaires were interviewer administered. Furthermore, the emergency room staff was aware of the conduct of the study and this may have influenced their actions.

\section{CONCLUSION}

In conclusion, respondents in this study perceived high quality of care provided at an ED of a tertiary level hospital in Morocco. A large part of patients were willing to return to the current facilities, and would recommend the facility to those who need emergency care. Pain management and staff-responsiveness are the major factors affecting satisfaction in emergency patients. Thus, improving the quality of these factors will improve the quality of emergency services for patients.

Based on the results obtained in this study, we would like to suggest paying special attention to Reception of patients in emergency departmentssince it seems to be a critical factor for patient satisfaction, and enhancing interpersonal relationship for better healthcare performance.

\section{DECLARATIONS}

Ethics approval and consent to participate :

Permission to conduct the study at the hospital was received from the hospital administration. All guidelines for the ethical conduct of the study were observed, respecting the rights of all participants in the study and ensuring that the participants were aware that they had the right to refuse and or withdraw at any time without any adverse consequences.

Consent for publication: Not applicable

Availability of data and material :The datasets during and/or analysed during the current study available from the corresponding author on reasonable request.

Competing interests : The authors declare that they have no competing interests.

Funding: Not applicable

Authors' contributions: 
E B performed the statistical analysis of the patient data and was a major contributor in writing the manuscript, S Z, M M and L B participate in the study concept and design, acquisition of the data and statistical analysis. A $\mathrm{B}, \mathrm{J} \mathrm{K}$ and $\mathrm{S} \mathrm{E}$ participated in acquisition of the data.All authors read and approved the final manuscript

\section{Acknowledgements: v}

[1] Sharma S.K., Kamra P.K. Patient satisfaction with nursing care in public and private hospitals. Nursing and Midwifery Research Journal, 2013;9 (3):130-141.

[2] Shirley E.D., Sanders J.O. Patient satisfaction: implications and predictors of success. The Journal of Bone and Joint Surgery. 2013; 95 (10).

[3] Ley P. Satisfaction, compliance, and communication. Br J Clin Psychol 1982;21:241-54.

[4] Forster HP, Schwartz J, DeRenzo E. Reducing legal risk by practicing patient-centered medicine. Arch Intern Med 2002;162: 1217-9.

[5] Haddad, Slim, Fournier, Pierre, Machouf, Nimaa, Yatara, Fassinet, 1998. What does quality mean to lay people? Community perceptions of primary healthcare services in Guinea. Social Science Medicine 47, 381-394.

[6] Margolis, Stephen A., Al-Marzouqi, Sumayya, Revel, Tony, Reed, Richard L., 2003. Patient satisfaction with primary health care services in the United Arab Emirates. International Journal for Quality in Health Care 15, 241-249.

[7] Press, Irwin, 2006. Patient Satisfaction: Understanding and Managing the Experience of Care. Health Administration Press, Chicago.

[8] Carr-Hill, Roy.A., 1992. The measurement of patient satisfaction. Journal of Public Health Medicine 14, 236-249.

[9] Trout A, Magnusson AR, Hedges JR. Patient satisfaction investigations and the emergency department: what does the literature say? Acad Emerg Med 2000;7:695-709.

[10] Turris, S.A., 2005. Unpacking the concept of patient satisfaction: a feminist analysis. Journal of Advanced Nursing. 50 (3), 293-298.

[11] Washam, C., 2009. Study: treatment satisfaction tied to language and culture: Spanish-speaking Latinas express more regret over breast-cancer surgery than women of other ethnicities do. Oncology Times 31 (3), 19-20.

[12] Hofstede, G. (1984), Culture's consequences. London: Sage.

[13] Ross CK, Steward CA, Sinacore JM. A comparative study of seven measures of patient satisfaction. Med Care 1995;33:392-406.

[14] Peres-Neto PR, Jackson DA, Somers KM: Giving meaningful interpretation to ordination axes: assessing loading significance in principal component analysis. Ecology 2003, 84:2347-2363.

[15] Mohanan, K., Kaur, S., Das, K., Bhalla, A., 2010. Patient satisfaction regarding nursing care at Emergency Outpatient Department in a tertiary care hospital. Journal of Mental Health \& Human Behaviour. 15 (1), 54-58.

[16] Dzomeku, V.M., Ba-Etilayoo, A., Perekuu, T., Mantey, R.E., 2013. In-patient satisfaction with nursing care: a case study at Kwame Nkrumah University of Science and Technology hospital. International Journal of Research in Medical and Health Sciences. 2 (1), 19-24.

[17] Dagger, T.S., Sweeney, J.C., \& Johnson, L.W. (2007). A hierarchical model of health service quality: scale development and investigation of an integrated model. Journal of Service Research, 10(2), 123-142.

[18] Welch SJ. Twenty years of patient satisfaction research applied to the emergency department: a qualitative review. Am J Med Qual 2010;25:64-72.

[19] Tang, W.M., Soong, C., Lim, W.C., 2013. Patient satisfaction with nursing care: a descriptive study using interaction model of client health behavior. International Journal of Nursing Science. 3 (2), 51-56.

[20] Muntlin A, Carlsson M, Gunningberg L. Barriers to change hindering quality improvement: the reality of emergency care. J Emerg Nurs 2010;36:317-23.

[21] Downey LV, Zun LS. The correlation between patient comprehension of their reason for hospital admission and overall patient satisfaction in the emergency department. J Natl Med Assoc 2010;102:63743.

[22] Trout A, Magnusson AR, Hedges JR. Patient satisfaction investigations and the ED: what does the literature says. Acad Emerg Med 2000;7:695-708.

[23] Boudreaux ED, O’Heal EL. Patient satisfaction in the ED: review of literature. J Emerg Med 2004;26:1326.

[24] Taylor DM, Wolfe R, Cameron PA. Analysis of complaints lodged by patients attending Victorian hospitals, 1997-2001. Med J Aust 2004; 181: 31-35. 
[25] Taylor DM, Wolfe R, Cameron PA. Complaints from emergency department patients largely result from treatment and communication problems. Emerg Med 2002; 14: 43-49.

[26] B Sahin, M Tatar. Factors affecting use of resources for asthma patients. J Med Syst. 2006;30(5):9.

[27] Donabedian A. The quality of care. How can it be assessed? JAMA. 1988;260(12):1743-48.

[28] Tokunaga J, Imanaka Y, Nobutomo K. Effects of patient demands on satisfaction with Japanese hospital care. Int J Qual Health Care. 2000;12(5):395-401.

[29] Aragon, S.J., Gesell, S.B., 2003. A patient satisfaction theory and its robustness across gender in emergency departments: a multigroup structural equation modeling investigation. American Journal of Medical Quality. 18 (3), 229-241.

[30] Todd KH, Ducharme J, Choiniere M, et al. Pain in the emergency department: results of the pain and emergency medicine initiative (PEMI) multicenter study. J Pain 2007;8:460-6.

[31] Tanabe P, Buschmann M. A prospective study of ED pain management practices and the patient's perspective. J Emerg Nurs 1999;25: 171-7.

[32] Motov SM, Khan AN. Problems and barriers of pain management in the emergency department: are we ever going to get better? J Pain Res 2008; 2:5-11.

[33] Viccellio P, Schneider SM, Asplin B, et al. Emergency department crowding: high-impact solutions. American College of Emergency Website. Available at: http://www.acep.org/workarea/download asset.aspx?id=37960. Accessed July 7, 2009.

[34] Bolton RN.A dynamicmodel of the duration of customer's relation-ship with a continuous service provider: the role of satisfaction. Mark Sci 1998;18:45-65.

[35] Maister DH. The psychology of waiting lines. Available at: http:// davidmaister.com/articles/5/52/. Accessed July 7, 2009.

[36] Arneill, A., Devlin, A.S., 2002. Perceived quality of care: the influence of the waiting room environment Journal of Environmental Psychology 22, 345-360.

[37] Chou, S., Chen, T., Woodard, B., Yen, M., 2005. Using SERVQUAL to evaluate quality disconfirmation of nursing services in Taiwan. The Journal of Nursing Research : JNR. 13 (2), 75-83.

Table 1: Characteristics of participants

\begin{tabular}{|c|c|c|c|c|c|}
\hline & \multicolumn{2}{|c|}{$\begin{array}{c}\text { Very dissatisfied to } \\
\text { dissatisfied }\end{array}$} & \multicolumn{2}{|c|}{ Satisfied to very satisfied } & \multirow[t]{2}{*}{$\mathrm{p}$} \\
\hline & $\mathrm{n}$ & $\%$ & $\mathrm{n}$ & $\%$ & \\
\hline \multicolumn{5}{|l|}{ Gender } & $<10^{-3}$ \\
\hline Male & 105 & $87.5 \%$ & 120 & $57.1 \%$ & \\
\hline Female & 15 & $12.5 \%$ & 90 & $42.9 \%$ & \\
\hline \multicolumn{5}{|c|}{ Age in years } & 0.03 \\
\hline$<25$ & 45 & $50.0 \%$ & 30 & $14.3 \%$ & \\
\hline$[25-40[$ & 15 & $16.7 \%$ & 60 & $28.6 \%$ & \\
\hline$[40-60[$ & 15 & $16.7 \%$ & 30 & 14.3 & \\
\hline$\geq 60$ & 15 & $16.7 \%$ & 90 & $42.9 \%$ & \\
\hline \multicolumn{5}{|c|}{ Higher education } & $<10^{-3}$ \\
\hline Yes & 75 & $62.5 \%$ & 105 & $50.0 \%$ & \\
\hline No & 45 & $37.5 \%$ & 105 & $50.0 \%$ & \\
\hline \multicolumn{5}{|c|}{ Waiting time in minutes } & $<10^{-3}$ \\
\hline$<15$ & 15 & $25.0 \%$ & 120 & $57.1 \%$ & \\
\hline$[15-45[$ & 15 & $25.0 \%$ & 75 & $35.7 \%$ & \\
\hline$\geq 45$ & 30 & $50.0 \%$ & 15 & $7.1 \%$ & \\
\hline
\end{tabular}


Table 2: Level of satisfaction with patient satisfaction items in the emergency department. Item

Satisfaction \%

Courtesy of the nurses

(satisied to very satisfied)

Courtesy of the doctors

$94.4 \%$

$94.4 \%$

Staff's reactivity

$94.1 \%$

Privacy provided during the stay in emergency

department

$92.9 \%$

Technical skills of nurses $\quad 90.5 \%$

Technical skills of doctors $\quad 90.5 \%$

Staff assessment of pain $\quad 85.7 \%$

Cleanliness in the Emergency department $\quad 84.6 \%$

Delay of response to pain $\quad 84.2 \%$

Treatment received for pain $\quad 84.2 \%$

Comfort of the waiting area $\quad 80.0 \%$

Availability of personnel in waiting area $\quad 76.5 \%$

Courtesy of administrative staff $\quad 76.2 \%$

Perception of waiting time $\quad 72.7 \%$

Information given about health $\quad 70.0 \%$

Document provided during the stay in emergency $\quad 70.0 \%$

department

$61.5 \%$

Table 3: Patient satisfaction factors elicited by principal components analysis (variance cumulative: 82.6\% : Cronbach's alpha: 0.864)

\begin{tabular}{|c|c|c|}
\hline $\begin{array}{c}\text { Dimensions (variance } \\
\text { [variance cumulative], } \\
\text { Cronbach's alpha) }\end{array}$ & Item & Loading \\
\hline \multicolumn{3}{|c|}{ Pain management (36.6 [36.6],0.949) } \\
\hline & Treatment received for pain & 0.927 \\
\hline & Delay of response to pain & 0.914 \\
\hline & Staff assessment of pain & 0.905 \\
\hline \multicolumn{3}{|c|}{ Staff responsiveness (16.8 [53.4],0.891) } \\
\hline & Information given about health & 0.885 \\
\hline & Courtesy of the nurses & 0.712 \\
\hline & Courtesy of the doctors & 0.622 \\
\hline & Staff's reactivity & 0.607 \\
\hline & Technical skills of doctors & 0.543 \\
\hline \multicolumn{3}{|l|}{ Reception (12.9 [66.3],0.848) } \\
\hline & Availability of personnel in waiting area & 0.901 \\
\hline & Ease to giving information in waiting area & 0.841 \\
\hline \multicolumn{3}{|c|}{ Waiting time (9.4 [75.7],0.781) } \\
\hline & $\begin{array}{c}\text { Privacy provided during the stay in emergency } \\
\text { department }\end{array}$ & 0.804 \\
\hline & Perception of Waiting time & 0.780 \\
\hline & Comfort of the waiting area & 0.601 \\
\hline \multicolumn{3}{|c|}{ Administrative skills (6.9 [82.6],0.703) } \\
\hline & $\begin{array}{l}\text { Document provided during the stay in emergency } \\
\text { department }\end{array}$ & 0.864 \\
\hline & Courtesy of administrative staff & 0.733 \\
\hline
\end{tabular}

Table 4. Percentage of positive responses to patient satisfaction factors

\begin{tabular}{cc}
\hline Satisfaction factors & Positive responses \\
\hline Staff responsiveness & $80.0 \%$ \\
\hline
\end{tabular}




\begin{tabular}{cc}
\hline Administrative skills & $80.0 \%$ \\
Waiting time & $75.0 \%$ \\
Pain management & $71.4 \%$ \\
Reception & $61.5 \%$ \\
\hline
\end{tabular}

